\title{
Amelioration of LPS-Induced Inflammation Response in Microglia by AMPK Activation
}

\author{
Chin-Chen Chen, ${ }^{1}$ Jiun-Tsai Lin, ${ }^{2}$ Yi-Fang Cheng, ${ }^{2}$ Cheng-Yi Kuo, ${ }^{2}$ Chun-Fang Huang, \\ Shao-Hsuan Kao, ${ }^{3}$ Yao-Jen Liang, ${ }^{1,4}$ Ching-Yi Cheng, ${ }^{5}$ and Han-Min Chen ${ }^{1,2,4}$ \\ ${ }^{1}$ Institute of Applied Science and Engineering, Catholic Fu-Jen University, New Taipei City 24205, Taiwan \\ ${ }^{2}$ Energenesis Biomedical Co., Ltd., New Taipei City 24205, Taiwan \\ ${ }^{3}$ Institute of Biochemistry and Biotechnology, Chung Shan Medical University, Taichung City 40201, Taiwan \\ ${ }^{4}$ Department of Life Science, Catholic Fu-Jen University, New Taipei City 24205, Taiwan \\ ${ }^{5}$ Research Center for Industry of Human Ecology, Graduate Institute of Health Industry Technology, Department of Cosmetic Science, \\ Chang Gung University of Science and Technology, Taoyuan 33303, Taiwan
}

Correspondence should be addressed to Han-Min Chen; steven@energenesis-biomedical.com

Received 31 March 2014; Revised 22 May 2014; Accepted 30 May 2014; Published 17 June 2014

Academic Editor: Nicole Clarke

Copyright (C) 2014 Chin-Chen Chen et al. This is an open access article distributed under the Creative Commons Attribution License, which permits unrestricted use, distribution, and reproduction in any medium, provided the original work is properly cited.

\begin{abstract}
Adenosine $5^{\prime}$-monophosphate-activated protein kinase (AMPK) is a key regulator of cellular energy homeostasis via modulating metabolism of glucose, lipid, and protein. In addition to energy modulation, AMPK has been demonstrated to associate with several important cellular events including inflammation. The results showed that ENERGI-F704 identified from bamboo shoot extract was nontoxic in concentrations up to $80 \mu \mathrm{M}$ and dose-dependently induced phosphorylation of AMPK (Thr-172) in microglia BV2 cells. Our findings also showed that the treatment of BV2 with ENERGI-F704 ameliorated the LPS-induced elevation of IL-6 and TNF- $\alpha$ production. In addition, ENERGI-F704 reduced increased production of nitric oxide (NO) and prostaglandin E2 (PGE2) via downregulating the expression of inducible nitric oxide synthase (iNOS) and cyclooxygenase 2 (COX-2), respectively. Moreover, ENERGI-F704 decreased activated nuclear translocation and protein level of NF- $\kappa$ B. Inhibition of AMPK with compound C restored decreased NF- $\kappa$ B translocation by ENERGI-F704. In conclusion, ENERGI-F704 exerts inhibitory activity on LPS-induced inflammation through manipulating AMPK signaling and exhibits a potential therapeutic agent for neuroinflammatory disease.
\end{abstract}

\section{Introduction}

Homeostasis of proinflammatory and anti-inflammatory response in brain is shifted towards a proinflammatory state with age, so neuroinflammation has been implicated as an important etiological factor in several aging-related neurodegenerative diseases, such as Alzheimer's disease and Parkinson's disease [1-3]. Due to the involvement of inflammation in pathogenesis, many studies were devoted to the therapy of neurodegenerative diseases using anti-inflammatory strategies [4]. Microglia are myeloid-lineage cells residing in the central nervous system. As a neuron protector, microglia are sensitive to microenvironment and readily become activated in response to immunological stimuli, toxin, or injury [5]. Upon activation, however, microglia secrete a variety of proinflammatory cytokines or other cytotoxic factors, which are believed to exacerbate neurodegeneration. It has been reported that lipopolysaccharides (LPS) and/or interferon- $\gamma$ enhanced the production of NO in microglia via inducible nitric oxide synthase (iNOS) and caused neuron death within 48 hours [6]. In addition, the increased proinflammatory cytokines such as TNF- $\alpha$, IL- $1 \beta$, and IL- 6 in either cell culture or animal models induce neuron degeneration [7-12].

NF- $\kappa \mathrm{B}$, a transcriptional factor, regulates several proinflammatory cytokines and inflammation-related protein expression such as TNF- $\alpha$, IL- $1 \beta$, IL- 6 , COX-2, and iNOS [13]. Upon stimulation, activated I $\kappa$ B kinase (IKK) phosphorylates $\mathrm{I} \kappa \mathrm{B}$, which results in the dissociation of NF- $\kappa \mathrm{B}$ $\mathrm{I} \kappa \mathrm{B}$ complex and thereby translocation of active NF- $\kappa \mathrm{B}$ into nucleus. Activation of NF- $\kappa$ B has been found in several 
neurodegenerative diseases including Alzheimer's disease, Parkinson's disease, and Huntington's disease [14-16] and has also been considered as an important target for therapy of neurodegenerative diseases.

AMP-activated kinase (AMPK) is a key regulator of energy homeostasis and metabolic stress [17]. Conditions of glucose deprivation, ischemia, or oxidative stress activate AMPK through upstream kinases such as liver kinase $\mathrm{B} 1$ (LKB1) and $\mathrm{Ca}^{2+} /$ calmodulin dependent kinase kinase $\beta$ (CaMKK $\beta$ ) by phosphorylation on conserved Thr-172 residue of $\alpha$ subunit $[18,19]$. Upon activation, AMPK directly phosphorylated downstream targets such as acetylCoA carboxylase to inhibit anabolic pathways such as fatty acid/cholesterol synthesis, protein synthesis, and gluconeogenesis [20] and increase cellular ATP level. In particular, recent studies reveal that AMPK might also be involved in modulating inflammatory response [21-24]. It has been demonstrated that an AMPK activator, 5-aminoimidazole4-carboxamide ribose (AICAR), suppressed LPS-induced proinflammatory secretion and attenuated nuclear factor- $\kappa \mathrm{B}$ $(\mathrm{NF}-\kappa \mathrm{B})$ activation in glial cells [25].

In the present study, we investigated the anti-inflammatory effects of ENERGI-F704, a purine compound identified from bamboo (Phyllostachys edulis) shoot extract [26], in microglia BV2 cells stimulated by LPS. We examined the effects of ENERGI-F704 on AMPK activation. We also assessed its anti-inflammation functions by monitoring the secretion of proinflammatory cytokines, the production of NO and PGE2, and the expression of corresponding enzymes in various conditions. It was found that ENERGI-F704 might attenuate LPS-induced inflammation and the nuclear translocation of NF- $\kappa$ B via AMPK activation in BV2 cells.

\section{Materials and Methods}

2.1. Reagents. All reagents were purchased from SigmaAldrich (St. Louis, MO, USA) except where otherwise specified. Dulbecco's modified Eagle's medium (DMEM) and fetal bovine serum (FBS) were purchased from Invitrogen (Carlsbad, CA, USA). ENERGI-F704 was a proprietary compound generously provided by Energenesis Biomedical Co., Ltd. (New Taipei, Taiwan).

2.2. Cell Culture. The murine microglial cell line (BV2) was given by Professor Kao (Chung Shan Medical University, Taichung, Taiwan) and routinely maintained in Dulbecco's modified Eagle's medium (DMEM) supplemented with 10\% fetal bovine serum (FBS), $4 \mathrm{mM}$ L-glutamine, $2 \mathrm{mM}$ sodium pyruvate, and $100 \mu \mathrm{g} / \mathrm{mL}$ penicillin-streptomycin (Invitrogen GibcoBRL, Carlsbad, CA, USA). Cells were incubated at $37^{\circ} \mathrm{C}$ under $5 \% \mathrm{CO}_{2}$ and $95 \%$ relative humidity. The cells used in this experiment were between passages 3 and 8 .

2.3. In Vitro Cytotoxicity Assay. The cytotoxicity of ENERGIF704 in BV2 cells was analyzed by XTT assay. In Brief, BV2 cells were seeded into 96-well microplates in a density of $1 \times 10^{4}$ cells/well. After incubation overnight, cells were treated with various concentration of ENERGI-F704 (0, 5, $10,20,40$, or $80 \mu \mathrm{M})$ for $24 \mathrm{~h}$. After the end of treatment,
$125 \mu \mathrm{L}$ of XTT (2,3-bis-(2-methoxy-4-nitro-5-sulfophenyl)$2 \mathrm{H}$-tetrazolium-5-carboxanilide) reagent was added to the final concentration of $1 \mathrm{mg} / \mathrm{mL}$. Then, the plates were incubated at $37^{\circ} \mathrm{C}$ for further $4 \mathrm{~h}$ in the dark. The absorbance was measured at $490 \mathrm{~nm}$ with a reference wavelength set at $690 \mathrm{~nm}$ using VersaMax ELISA microplate reader (Molecular device, Sunnyvale, CA, USA). Data was presented as relative absorbance values to untreated cell.

2.4. Western Blot Assays. Cells were collected, washed twice with ice-cold PBS (PH 7.4), and lysed in cell lysis buffer containing $10 \mathrm{mM}$ Tris- $\mathrm{HCl} \mathrm{pH} \mathrm{7.5,} 150 \mathrm{mM} \mathrm{NaCl}, 1 \mathrm{mM}$ EDTA, $0.5 \%$ Triton-X 100, 1x protease inhibitor cocktail (Roche, Basel, Switzerland), and 1x PhosSTOP phosphatase inhibitor cocktail (Roche) at $4^{\circ} \mathrm{C}$ for $30 \mathrm{~min}$. Cell lysate was centrifuged at $15,000 \mathrm{~g}, 4^{\circ} \mathrm{C}$ for $1 \mathrm{~min}$, and the supernatant was stored at $-70^{\circ} \mathrm{C}$ until further analysis. $30 \mathrm{mg}$ of protein samples was subjected to $10 \%$ SDS-PAGE and subsequently transferred onto Immobilon polyvinylidene difluoride (PVDF) membranes (Millipore, Bedford, MA, USA). After blocking with 5\% BSA in PBS, the membranes were incubated with primary antibodies, including anti-phospho-AMPK (Thr172) antibody (1:2000, number 2535, Cell Signaling Technology, Danvers, MA, USA), anti-AMPK $\alpha 1$ antibody (1:2000, number 2603, Cell Signaling Technology), anti-iNOS antibody $(1: 2000$, number 2977 , Cell Signaling Technology), anti-COX-2 antibody ( $1: 2000$, number 12282 , Cell Signaling Technology), anti-p65 antibody (1:2000, number 8242, Cell Signaling Technology), or anti-actin antibody (1:5000, NB600-501, Novus Biologicals, Littleton, CO, USA) at $4^{\circ} \mathrm{C}$ overnight. Resulting membranes were washed and incubated with corresponding secondary antibodies coupled with horseradish peroxidase in 1:20000 dilution at room temperature for $1 \mathrm{~h}$. Chemiluminescence of the immunoreactive bands was developed by LumiFlash Prime Chemiluminescent Substrate, HRP (Visual Protein, Taipei, TW), and detected by Kodak XAR-5 film (Rochester, NY, USA). The images were scanned and quantified using Image J software (http://imagej.nih.gov/ij/).

2.5. Enzyme-Linked Immunosorbent Assay (ELISA). Production of proinflammatory cytokine and PGE2 was analyzed using ELISA assay. The supernatant of cell culture was harvested and assessed. The cytokines IL6 and TNF- $\alpha$ were evaluated using Mouse DuoSet ELISA kits (R\&D Systems, Minneapolis, MN, USA) and the extracellular PGE2 was assessed using Prostaglandin E2 parameter assay kit (R\&D Systems). All the manipulations were performed following the manufacturer's protocol.

2.6. Nitric Oxide Determination. Production of nitric oxide was measured using the Griess assay. In brief, $100 \mu \mathrm{L}$ of supernatant sample was mixed with equal volume of Griess reagent containing $1 \%$ sulfanilamide, $0.1 \% \mathrm{~N}$-(1-naphthyl)ethylenediamine dihydrochloride, and $5 \% \mathrm{H}_{3} \mathrm{PO}_{4}$. After $5 \mathrm{~min}$ incubation, the absorbance was measured at $550 \mathrm{~nm}$ with a reference wavelength set at $630 \mathrm{~nm}$ using VersaMax ELISA microplate reader. A standard curve made from a series of standard nitrite concentrations $(0,6.25,12.5$, 


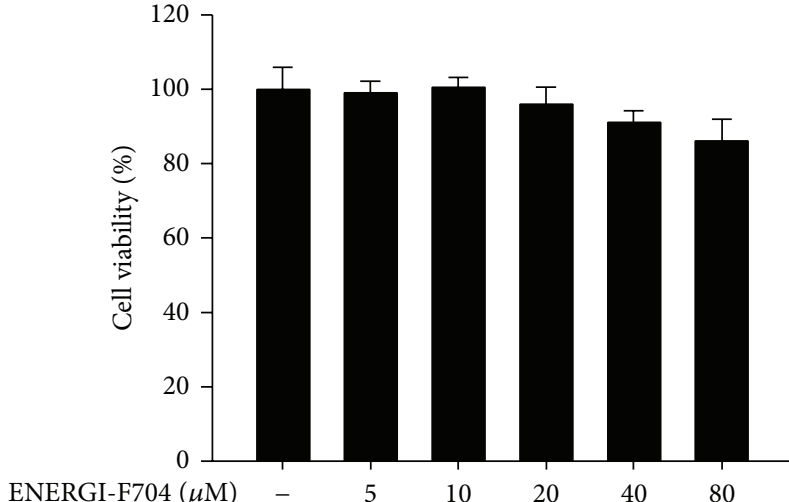

(a)

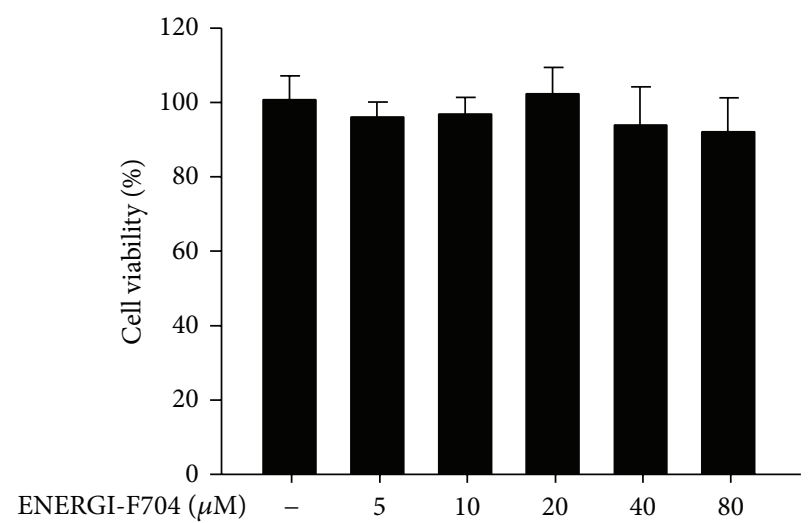

(b)

FIGURE 1: Cytotoxicity of ENERGI-F704. BV2 cells induced either without (a) or with (b) LPS were treated with indicated concentrations of ENERGI-F704 for $24 \mathrm{~h}$. The cell viability of each condition was analyzed using XTT assay. The relative cytotoxicity is calculated as relative absorbance values to untreated cell. Data are statistically analyzed by one-way ANOVA and presented as the mean \pm SEM of three independent experiments.

50, 66.7, 100, and $200 \mu \mathrm{M})$ was used for sample calibration.

2.7. NAD Assay. NAD level was determined by $\mathrm{NADH}$ cycling enzymatic reaction using NAD/NADH quantification colorimetric kit (Biovision, Milpitas, CA, USA) according to the manufacturer's instructions. In brief, $2 \times 10^{5}$ cells were harvested and extracted with $400 \mu \mathrm{L}$ NAD/NADH Extraction Buffer by two freeze/thaw cycles $(20 \mathrm{~min}$ on dry-ice, then $10 \mathrm{~min}$ at RT), followed by vortex and centrifugation at $14000 \mathrm{rpm}$ for $5 \mathrm{~min}$. The supernatants were examined for the total level of NAD plus NADH by mixing with NAD Cycling Mix for conversion of NAD to NADH and measured for the free NADH by heat decomposing of NAD at $60^{\circ} \mathrm{C}$ for $30 \mathrm{~min}$. The colorimetric assay of $\mathrm{NADH}$ was developed by adding $\mathrm{NADH}$ developer and it was incubated at RT for $1 \mathrm{~h}$. The absorbance was measured at $450 \mathrm{~nm}$ using VersaMax ELISA microplate reader (Molecular device, Sunnyvale, CA, USA). Data was presented as relative absorbance values to untreated cell. A standard curve made from a series of standard $\mathrm{NADH}$ amounts $(0,20,40,60,80$, and $100 \mathrm{pmol})$ was used for sample calibration. The NAD level was calculated as NAD = total of $\mathrm{NAD}+\mathrm{NADH}-\mathrm{NADH}$. The data were normalized with total cell lysate protein (NAD/mg protein) and presented as relative concentration to untreated cell.

2.8. Immunocytochemistry. Cells were cultured on glass coverslips in the DMEM based medium. The cultures were treated with LPS incorporating with ENERGI-F704 or compound $\mathrm{C}$ in indicated concentrations for $1 \mathrm{~h}$ at $37^{\circ} \mathrm{C}$. The cells were fixed with $4 \%$ paraformaldehyde and subsequently incubated with anti-p65 antibody $(1: 200$, number 8242 , cell Signaling Technology) at $4^{\circ} \mathrm{C}$ overnight followed by the incubation with Alex Fluor 488-labeled secondary antibody ( $1: 1000$, Abcam, Cambridge, UK) for $1 \mathrm{~h}$ at room temperature. The nuclei of cells were counterstained with DAPI. Coverslips were mounted with ibidi mounting medium (ibidi
GmbH, Martinsried, Germany) and the immunofluorescence was imaged by OLYMUS 1X71 inverted microscope. The resulting images were quantified using ImageJ software.

2.9. Statistical Analysis. All results were presented as means \pm SEM of three independent experiments. Statistical analysis was performed by one-way ANOVA or two-way ANOVA using SPSS software (Armonk, NY, USA).

\section{Results}

3.1. ENERGI-F704 Activates AMPK in BV2 Cells. We examined the cytotoxicity of ENERGI-F704 in microglial BV2 cells using XTT assay. As shown in Figure 1, ENERGI-F704 at concentrations up to $80 \mu \mathrm{M}$ exerted no toxic effect on the BV2 cells treated with or without LPS. We next determined the AMPK activating property of ENERGI-F704 in BV2 cells using Western blot analysis. According to Figure 2, a significant increase in the phosphorylation of AMPK was observed in the presence of ENERGI-F704 in a dose-dependent manner.

3.2. ENERGI-F704 Reduces Proinflammatory Cytokines Production in LPS-Induced BV2 Cells. AMPK has been reported for its role in suppressing inflammatory responses. Therefore, we next evaluated whether ENERGI-F704 suppresses the production of proinflammatory cytokines such as TNF- $\alpha$ and IL-6 in LPS-treated BV2 cells. LPS-treated BV2 cells were treated with either ENERGI-F704 or the pharmacological AMPK activator, 5-aminoimidazole-4-carboxamide $1-\beta$-Dribofuranoside (AICAR), for $24 \mathrm{~h}$. The changes in levels of TNF- $\alpha$ and IL- 6 were determined using ELISA assay. The exposure of BV-2 cells to LPS resulted in a significant secretion of IL- 6 and TNF- $\alpha$ after $24 \mathrm{~h}$ incubation (Figures $3(\mathrm{a})$ and $3(\mathrm{~b})$ ). The elevations in TNF- $\alpha$ and IL- 6 production 


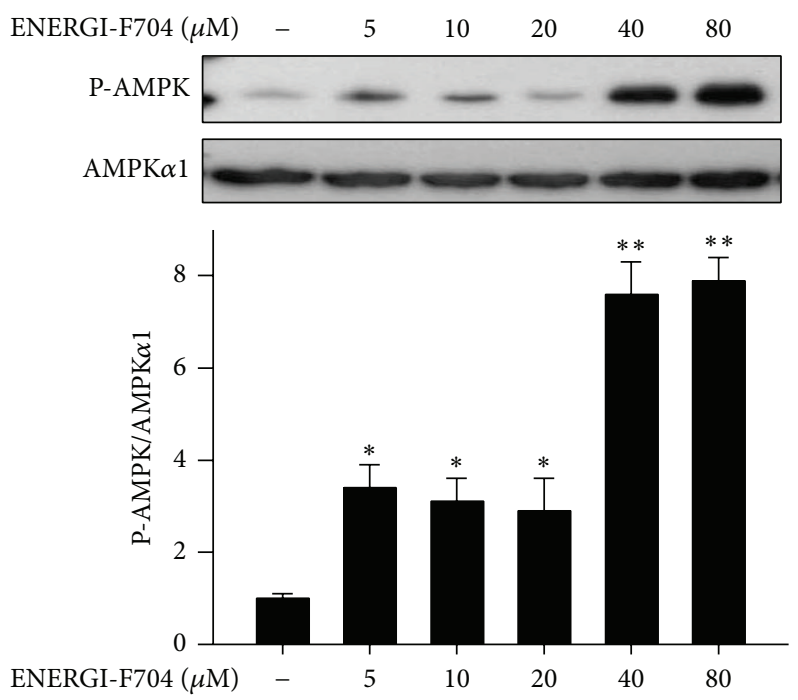

FIGURE 2: ENERGI-F704 activates AMPK in microglial BV2 cells. BV2 cells were treated with serial concentrations of ENERGI-F704 for 3 h. Cell lysates were used to determine the phosphorylation of AMPK using Western blot analysis. Data are presented as the mean \pm SEM of three independent experiments (one-way ANOVA; ${ }^{* *}, P<0.01$; specific comparison to vehicle treated control). Representative images of three independent experiments are shown.

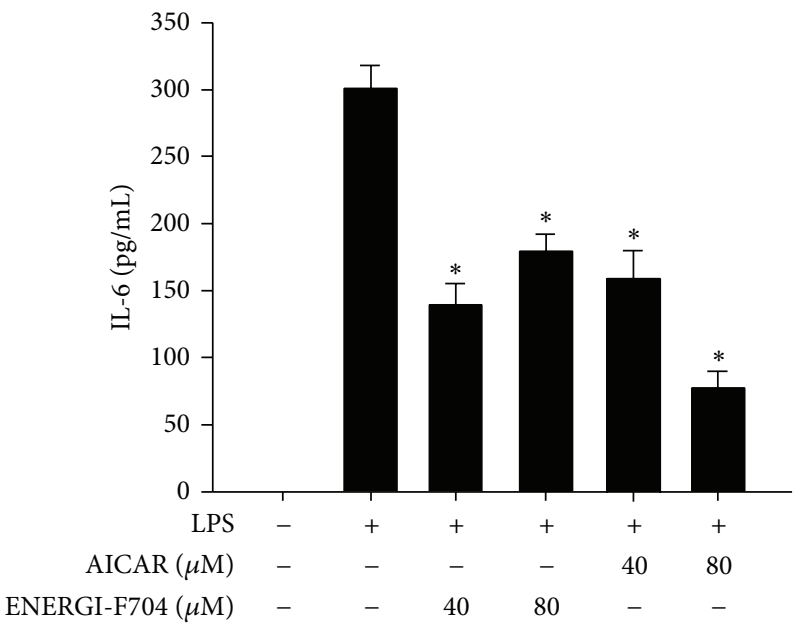

(a)

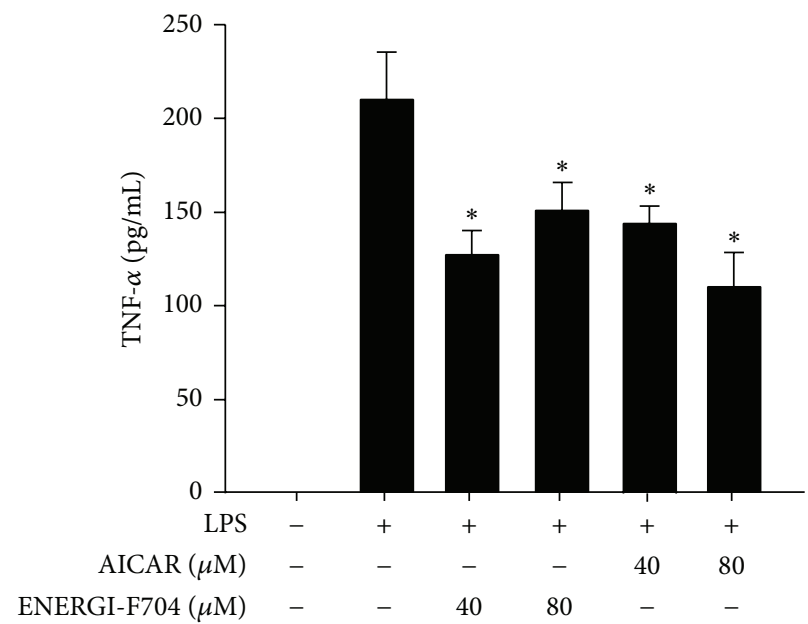

(b)

FIGURE 3: ENERGI-F704 reduced LPS-induced IL-6 and TNF- $\alpha$ secretion in BV2 cells. BV2 cells were incubated with $200 \mathrm{ng} / \mathrm{mL}$ LPS in the presence of ENERGI-F704 or AICAR for $24 \mathrm{~h}$. The levels of IL-6 (a) and TNF- $\alpha$ (b) in culture medium of each condition were accessed using ELISA analysis. Data are presented as the mean \pm SEM of three independent experiments (one-way ANOVA; ${ }^{*}, P<0.05$; specific comparison to LPS-treated control).

were reduced significantly in the presence of ENERGI-F704. A similar inhibitory phenomenon was observed in the cells treated with AICAR.

\subsection{ENERGI-F704 Suppresses NO Production and iNOS} Expression in LPS-Induced BV2 Cells. Nitric oxide (NO) acts as signaling molecule in inflammation. The excessive production of NO in response to LPS stimulation might lead to activation of apoptotic signaling in brain tissue [27]. To evaluate the effects of ENERGI-F704 on NO production induced by LPS, BV2 cells stimulated with LPS were treated with ENERGI-F704 or AICAR for $24 \mathrm{~h}$, and concentration of NO was analyzed. As shown in Figure 4(a), treatment with ENERGI-F704 at concentrations of 40 and $80 \mu \mathrm{M}$ significantly inhibited NO production of LPS-treated BV-2 cells, whereas AICAR inhibited NO production as well. To explore the mechanism underlying inhibitory effect of ENERGI-F704 on LPS-induced NO production, expression of iNOS in each experimental group was assessed using Western blotting. The elevated expressions of iNOS in LPS-induced BV2 cells were significantly reduced by treatment with ENERGI-F704 or AICAR (Figure 4(b)), whereas use of AMPK inhibitor, 


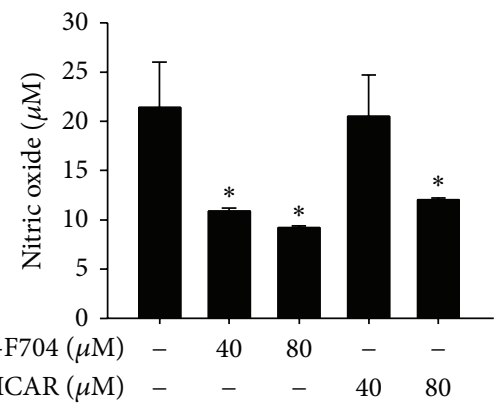

(a)

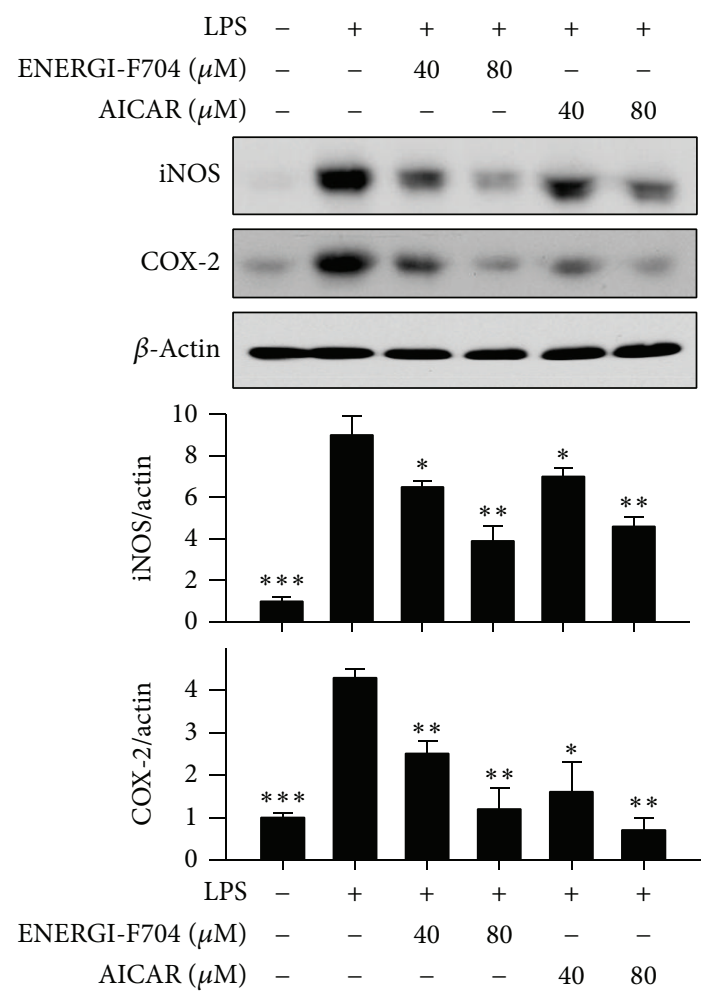

(b)

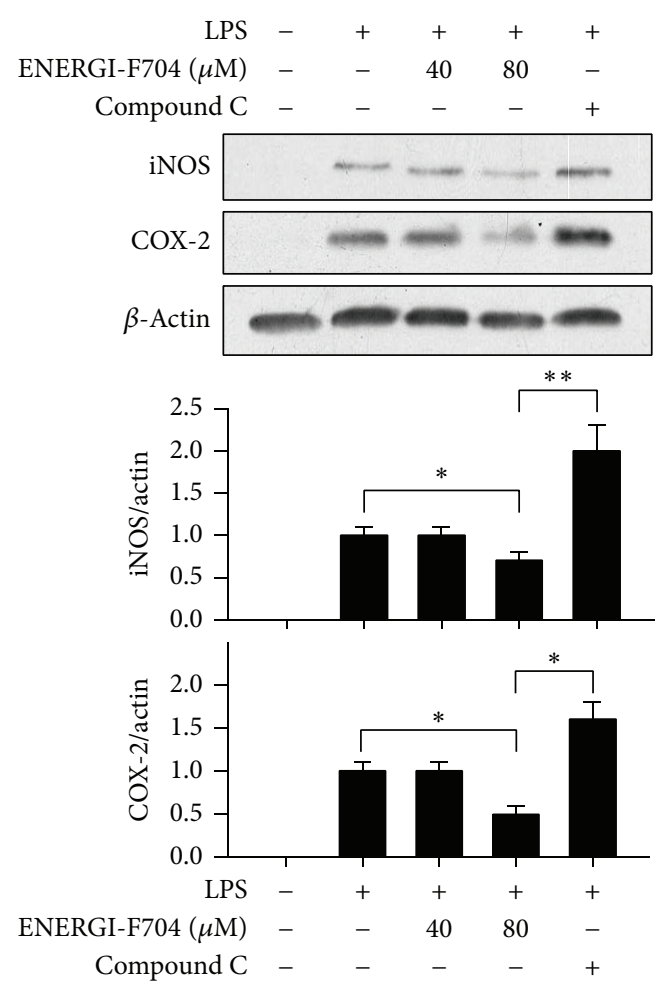

(c)

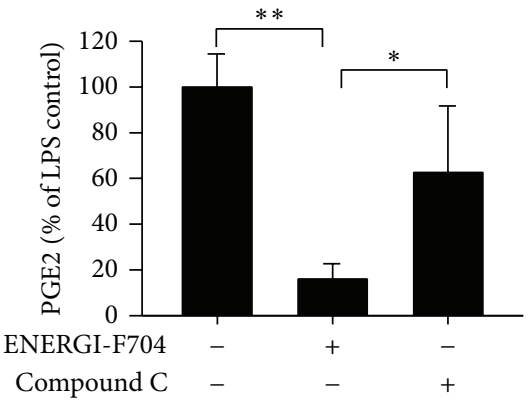

(d)

FIGURE 4: ENERGI-F704 decreases LPS-induced NO, iNOS, COX-2, and PGE2 production in BV2 cells. BV2 cells were stimulated with $200 \mathrm{ng} / \mathrm{mL}$ LPS and subsequently treated with either ENERGI-F704 or AICAR for $24 \mathrm{~h}$. (a) Levels of NO in the culture of BV2 cell were determined. (b) After treatments, cell lysates were used to determine the level of iNOS and COX-2 using Western blotting. (c) LPS-treated BV2 cells were treated with ENERGI-F704 in cotreatment with or without compound C for $24 \mathrm{~h}$. Cell lysates were used to determine the level of iNOS and COX-2 using Western blotting. (d) LPS-induced BV2 cells were treated with ENERGI-F704 in cotreatment with or without compound C for $48 \mathrm{~h}$, and the level of PGE2 in the culture medium was determined. Data are presented as the mean \pm SEM of three independent experiments (two-way ANOVA; ${ }^{*},{ }^{* *}$, and ${ }^{* * *}, P<0.05, P<0.01$, and $P<0.01$; specific comparison to LPS-treated control). Representative images of three independent experiments are shown. 
compound $\mathrm{C}$, led to negatively compensated expression of iNOS (Figure 4(c)).

3.4. ENERGI-F704 Inhibited LPS-Induced Cyclooxygenase 2 Expression and PGE2 Production. We further evaluated the effect of ENERGI-F704 on COX-2 expression in BV2 cells challenged with LPS using Western blot assay. As shown in Figure 4(b), the expression of COX-2 was upregulated upon LPS stimulation. The upregulated expression of COX2 was ameliorated by ENERGI-F704 or AICAR (Figure 4(b)), whereas the treatment with compound $\mathrm{C}$ remarkably reversed the suppression (Figure 4(c)). As expected, when measuring the product of COX-2, as shown in Figure 4(d), the concentration of extracellular PGE2 in LPS-induced BV2 cells was diminished by ENERGI-F704, which can be offset in the presence of compound $\mathrm{C}$.

3.5. ENERGI-F704 Attenuates LPS-Induced Nuclear Translocation and Production of $N F-\kappa B$. NF- $\kappa \mathrm{B}$ is known for its critical role in inflammation through regulating transcription of proinflammatory cytokines such as IL- $1 \beta$, IL- 6 , TNF- $\alpha$, and iNOS. To examine the effects of ENERGI-F704 on NF$\kappa \mathrm{B}$ activation, LPS-stimulated BV2 cells were treated with ENERGI-F704 for $1 \mathrm{~h}$ and examined for nuclear translocation of NF- $\kappa \mathrm{B}$. As shown in Figure $5, \mathrm{NF}-\kappa \mathrm{B}$ stained green retained in cytosol and translocated into nuclei in response to LPS stimulation. The treatment of LPS-induced BV2 cells with ENERGI-F704 attenuated the translocation of NF- $\kappa \mathrm{B}$ to nuclei. The inhibitory effect of ENERGI-F704 on NF- $\kappa$ B translocation was reversed in the presence of compound $\mathrm{C}$. Furthermore, our data revealed that the expression level of P65 was reduced significantly in a dose-dependent manner (Figure 5(c)).

Activation of AMPK leads to the deacetylation activity of SIRT1 mediated by the increase of $\mathrm{NAD}^{+}$and acetylation of P65 is required for the stability of $\mathrm{NF}-\kappa \mathrm{B}[28-30]$. We next determined the effect of ENERGI-F704 on the NAD ${ }^{+}$ level. As shown in Figure 6, the treatment with ENERGIF704 dose-dependently increased the level of $\mathrm{NAD}^{+}$. Interestingly, increased level of $\mathrm{NAD}^{+}$in response to ENERGI-F704 treatment was largely reversed in the presence of compound C.

\section{Discussion}

Accumulating evidence shows that AMPK is a repressor of inflammation. However, there are limited studies addressed on the effect of AMPK activators on LPS-induced microglia. In the present study, ENERGI-F704, a proprietary compound identified from bamboo shoots extract, exerts AMPK activation activity in human microglial cell model BV2. ENERGI-F704 suppressed LPS-induced IL- 6 and TNF- $\alpha$ secretion. Moreover, ENERGI-F704 decreased LPS-induced iNOS and COX-2 expression as well as the production of $\mathrm{NO}$ and PGE2 in BV2 cells. In the testing condition, our data suggest ENERGI-F704 with anti-inflammatory activity without apparent cytotoxicity. In fact, our previous study has reported that ENERGI-F704 can trigger the phosphorylation of AMPK in human umbilical vein endothelial cells [26]. All the results indicate that ENERGI-F704 acts as an AMPK activator to ameliorate that the NF- $\kappa \mathrm{B}$-involved inflammation response is reliable and not cell type restricted.

Some AMPK activators such as AICAR and metformin have also been demonstrated for their potential to modulate inflammation via NF- $\kappa \mathrm{B}[25,31,32]$. Our results had showed ENERGI-F704 as a feasible mean to attenuate LPS-induced inflammatory responses in BV2 and other cell lines. As the anti-inflammatory effects of ENERGI-F704 were diminished in the presence of AMPK inhibitor, compound C, it again suggests that the amelioration of LPS-induced inflammation in microglia BV2 cells by ENERGI-F704 is mediated by AMPK activation. In addition, the activation of AMPK can activate SIRT1 activity via increasing intracellular $\mathrm{NAD}^{+}$levels [28]. It has been demonstrated that SIRT1 could deacetylate p65 subunit of NF- $\kappa \mathrm{B}$ complex at lysine 310 and consequently enhance the set-mediated methylation of lysines 314 and 315 $[29,30]$. Moreover, the methylation of lysines 314 and 315 resulted in degradation of p65 through triggering ubiquitinproteasome system. In the present study, we did observe an increase in the level of NAD and a reduction in the level of p65 subunit under the treatment of ENERGI-F704 (Figure $4(d))$. Therefore, it is possible that destabilization of p65 protein might be another way of ENERGI-F704 to modulate $\mathrm{NF}-\kappa \mathrm{B}$ activity. Indeed, the LPS-induced expression of p65 downstream targets, iNOS and COX-2, can be suppressed in the presence of ENERGI-F704 (Figures 4(b) and 4(c)).

Numerous studies showed that manipulation of NF$\kappa \mathrm{B}$ signaling provides beneficial effects in treating neuron injury. It has been examined that suppression of NF- $\kappa \mathrm{B}$ activity by using IKK inhibitors, AS602868 and BAY 117082, exerts long-lasting protection of primary neurons and oligodendrocytes under N-methyl-D-aspartate induced excitotoxicity $[33,34]$. In a mouse model of focal cerebral ischemia, transgenic expression of NF- $\kappa \mathrm{B}$ suppressor or pharmacological inhibitor of IKK reduced the infarct size [35]. Besides neuron injury, activation of $N F-\kappa B$ has been found in several aging-related neurodegenerative diseases including Alzheimer's disease and Parkinson's disease, which was considered as a pivotal target for therapy of neurodegenerative diseases $[14,15]$. In addition, recent studies further revealed that the neuron immune crosstalk of NF- $\kappa \mathrm{B}$, IKK, and microglia in hypothalamus is important in systemic ageing progression, so immune inhibition can be a potential strategy for lifespan extension [36]. Considering AMPK activation effectively manipulating the NF- $\kappa$ B signaling, AMPK activators, including ENERGI-F704, are potential therapeutic agents for neurodegenerative diseases. Further studies are awaited to elucidate the underlying mechanism of ENERGIF704 on AMPK.

\section{Conclusions}

In conclusion, ENERGI-F704 suppressed inflammatory responses and induced AMPK activation in LPS-treated BV-2 cells. Anti-inflammatory effect of ENERGI-F704 was attributed to modulating the nuclear translocation and stability of NF- $\kappa$ B. The anti-inflammatory effects of ENERGI-F704 were diminished in the presence of AMPK inhibitor. It 

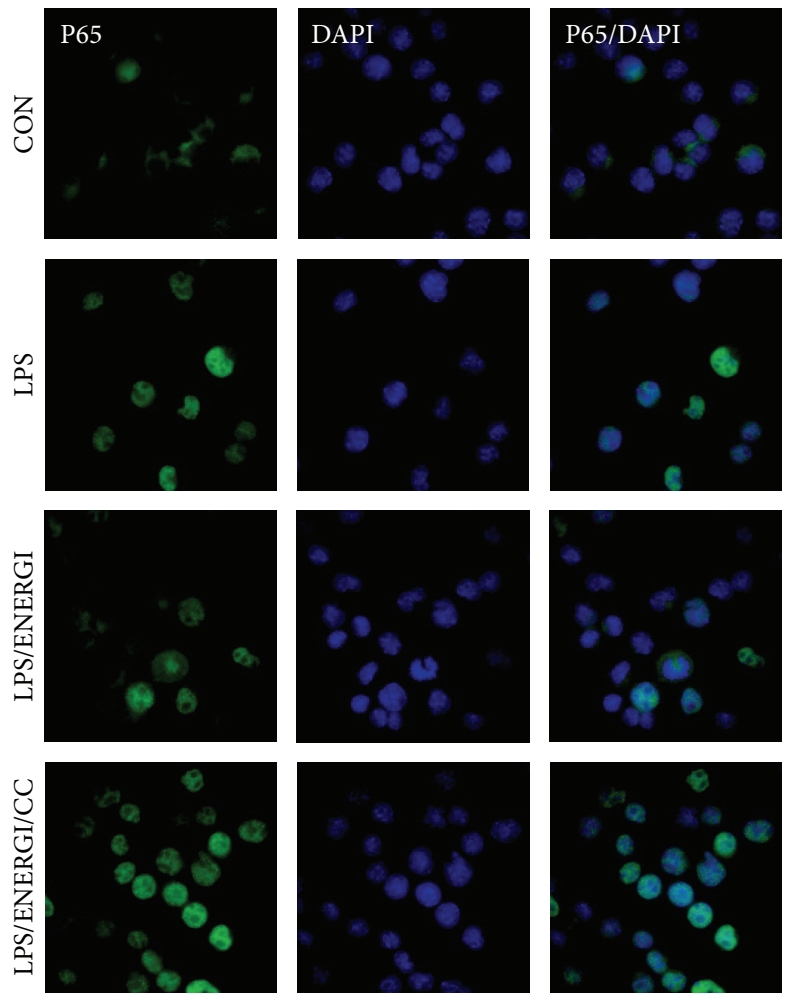

(a)

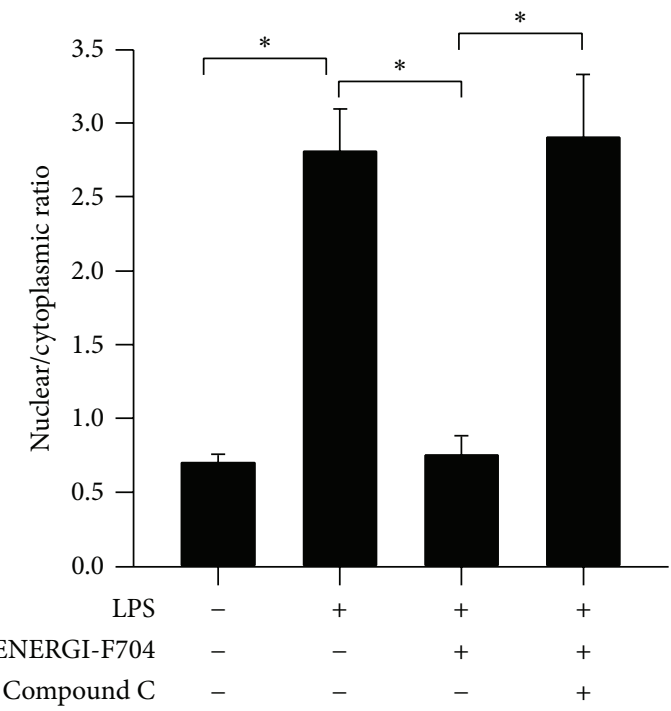

(b)

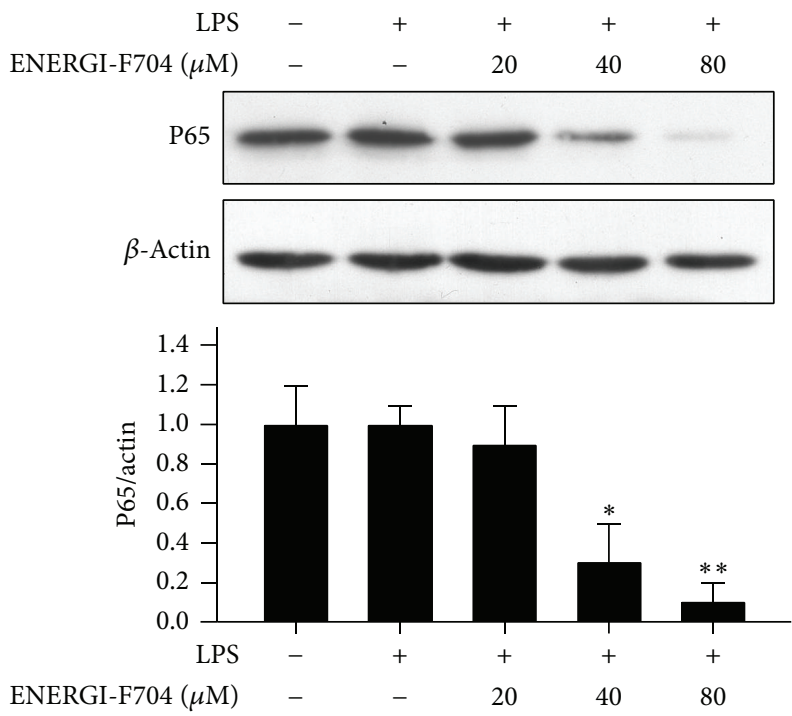

(c)

FIGURE 5: ENERGI-F704 attenuates LPS-induced nuclear translocation and production of NF- $\kappa$ B in BV2 cells. BV2 cells were stimulated with $200 \mathrm{ng} / \mathrm{mL}$ LPS and subsequently treated with ENERGI-F704 incorporating with or without compound C for 1 h. (a) After treatments, cells were fixed for immunocytochemical staining. NF- $\kappa$ B and nuclei were visualized using Alexa Fluor 488 (green) and DAPI (blue), respectively. (b) Ratio of nuclear: cytoplasmic immunofluorescence of NF- $\kappa$ B was assessed by microscopy image and quantified using ImageJ software. Ratio $<1$ indicates brighter cytoplasmic staining for NF- $\kappa \mathrm{B}$, whereas ratios $>1$ indicate brighter nuclear staining for NF- $\kappa$ B. (c) BV2 cells were incubated with $200 \mathrm{ng} / \mathrm{mL}$ LPS in the presence of ENERGI-F704 for $24 \mathrm{~h}$. After treatments, cell lysates were used to determine the levels of NF- $\kappa$ B using Western blotting. Data are presented as the mean \pm SEM of three independent experiments (one-way ANOVA; ${ }^{*}$ and ${ }^{* *}$, $P<0.05$ and $P<0.01$; specific comparison to LPS-treated control). Representative images of three independent experiments are shown. 


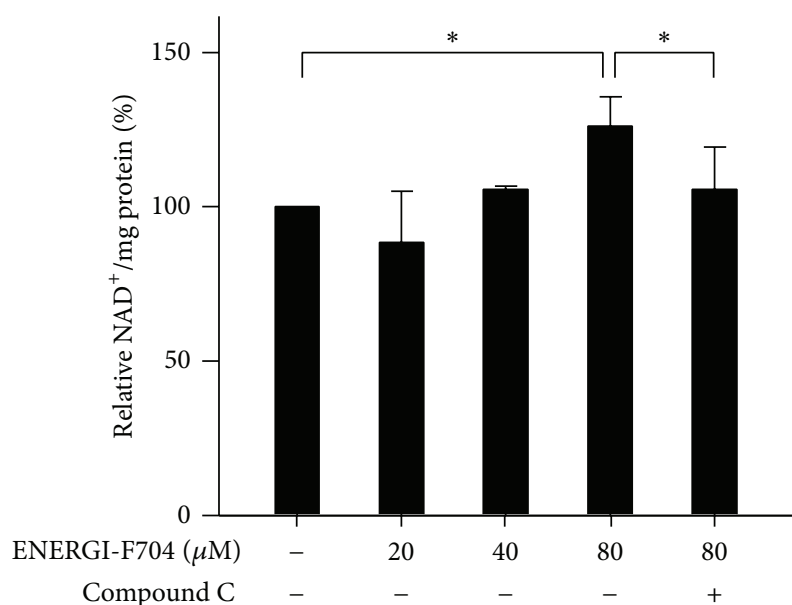

FIGURE 6: ENERGI-F704 increases the level of NAD in BV2 cells. BV2 cells were incubated with $200 \mathrm{ng} / \mathrm{mL}$ LPS in the presence of ENERGI-F704 or compound C for $24 \mathrm{~h}$. Cell lysates collected from each condition were used to determine the level of NAD using NAD/NADPH colorimetric analysis. Data are presented as the mean \pm SEM of three independent experiments (one-way ANOVA; ${ }^{*}, P<$ $0.05)$.

is suggested that ENERGI-F704 has a potential to act as anti-inflammatory agent for treating neuroinflammatory diseases through AMPK activation. Further studies are necessary to elucidate the actual mechanism underlying antiinflammatory activity of ENERGI-F704.

\section{Conflict of Interests}

The authors declare that there is no conflict of interests regarding the publication of this paper.

\section{Authors' Contribution}

Chin-Chen Chen and Jiun-Tsai Lin contributed equally to this work.

\section{References}

[1] C. Holmes, C. Cunningham, E. Zotova et al., "Systemic inflammation and disease progression in Alzheimer disease," Neurology, vol. 73, no. 10, pp. 768-774, 2009.

[2] H.-M. Gao, B. Liu, W. Zhang, and J.-S. Hong, "Synergistic dopaminergic neurotoxicity of MPTP and inflammogen lipopolysaccharide: relevance to the etiology of Parkinson's disease," FASEB Journal, vol. 17, no. 13, pp. 1957-1959, 2003.

[3] X.-G. Luo, J.-Q. Ding, and S.-D. Chen, "Microglia in the aging brain: relevance to neurodegeneration," Molecular Neurodegeneration, vol. 5, no. 1, article 12, 2010.

[4] B. Liu and J.-S. Hong, "Role of microglia in inflammationmediated neurodegenerative diseases: mechanisms and strategies for therapeutic intervention," Journal of Pharmacology and Experimental Therapeutics, vol. 304, no. 1, pp. 1-7, 2003.

[5] G. W. Kreutzberg, "Microglia: a sensor for pathological events in the CNS," Trends in Neurosciences, vol. 19, no. 8, pp. 312-318, 1996.
[6] A. Bal-Price and G. C. Brown, "Inflammatory neurodegeneration mediated by nitric oxide from activated glia-inhibiting neuronal respiration, causing glutamate release and excitotoxicity," Journal of Neuroscience, vol. 21, no. 17, pp. 6480-6491, 2001.

[7] L. Yuan and A. H. Neufeld, "Tumor necrosis factor-alpha: a potentially neurodestructive cytokine produced by glia in the human glaucomatous optic nerve head," Glia, vol. 32, pp. 42$50,2000$.

[8] U. Schlomann, S. Rathke-Hartlieb, S. Yamamoto, H. Jockusch, and J. W. Bartsch, "Tumor necrosis factor $\alpha$ induces a metalloprotease-disintegrin, ADAM8 (CD 156): implications for neuron-glia interactions during neurodegeneration," Journal of Neuroscience, vol. 20, no. 21, pp. 7964-7971, 2000.

[9] K. Hemmer, L. Fransen, H. Vanderstichele, E. Vanmechelen, and P. Heuschling, "An in vitro model for the study of microgliainduced neurodegeneration: involvement of nitric oxide and tumor necrosis factor- $\alpha$," Neurochemistry International, vol. 38, no. 7, pp. 557-565, 2001.

[10] I. Figiel and K. Dzwonek, "TNF $\alpha$ and TNF receptor 1 expression in the mixed neuronal-glial cultures of hippocampal dentate gyrus exposed to glutamate or trimethyltin," Brain Research, vol. 1131, no. 1, pp. 17-28, 2007.

[11] C. C. Ferrari, M. C. Pott Godoy, R. Tarelli, M. Chertoff, A. M. Depino, and F. J. Pitossi, "Progressive neurodegeneration and motor disabilities induced by chronic expression of IL- $1 \beta$ in the substantia nigra," Neurobiology of Disease, vol. 24, no. 1, pp. 183193, 2006.

[12] R. A. Quintanilla, D. I. Orellana, C. González-Billault, and R. B. Maccioni, "Interleukin-6 induces Alzheimer-type phosphorylation of tau protein by deregulating the cdk5/p35 pathway," Experimental Cell Research, vol. 295, no. 1, pp. 245-257, 2004.

[13] P. J. Barnes and M. Karin, "Nuclear factor- $\kappa \mathrm{B}$ - a pivotal transcription factor in chronic inflammatory diseases," New England Journal of Medicine, vol. 336, no. 15, pp. 1066-1071, 1997.

[14] G. P. García-Ospina, M. Jiménez-Del Río, F. Lopera, and C. Vélez-Pardo, "Neuronal DNA damage correlates with a positive detection of c-Jun, nuclear factor $\kappa \mathrm{B}$, p53 and Par- 4 transcription factors in Alzheimer's disease," Revista de Neurologia, vol. 36, no. 11, pp. 1004-1010, 2003.

[15] S. Hunot, B. Brugg, D. Ricard et al., "Nuclear translocation of NF- $\kappa \mathrm{b}$ is increased in dopaminergic neurons of patients with Parkinson disease," Proceedings of the National Academy of Sciences of the United States of America, vol. 94, no. 14, pp. 7531-7536, 1997.

[16] M. Napolitano, D. Zei, D. Centonze et al., "NF-kB/NOS crosstalk induced by mitochondrial complex II inhibition: implications for Huntington's disease," Neuroscience Letters, vol. 434, no. 3, pp. 241-246, 2008.

[17] D. G. Hardie, "Minireview: the AMP-activated protein kinase cascade: the key sensor of cellular energy status," Endocrinology, vol. 144, no. 12, pp. 5179-5183, 2003.

[18] M. J. Abbott, A. M. Edelman, and L. P. Turcotte, "CaMKK is an upstream signal of AMP-activated protein kinase in regulation of substrate metabolism in contracting skeletal muscle," The American Journal of Physiology: Regulatory Integrative and Comparative Physiology, vol. 297, no. 6, pp. R1724-R1732, 2009.

[19] A. Woods, S. R. Johnstone, K. Dickerson et al., "LKB1 is the upstream kinase in the AMP-activated protein kinase cascade," Current Biology, vol. 13, no. 22, pp. 2004-2008, 2003.

[20] D. G. Hardie, S. A. Hawley, and J. W. Scott, "AMP-activated protein kinase-development of the energy sensor concept," Journal of Physiology, vol. 574, no. 1, pp. 7-15, 2006. 
[21] S. Galic, M. D. Fullerton, J. D. Schertzer et al., "Hematopoietic AMPK $\beta 1$ reduces mouse adipose tissue macrophage inflammation and insulin resistance in obesity," Journal of Clinical Investigation, vol. 121, no. 12, pp. 4903-4915, 2011.

[22] S. J. Park, K. S. Lee, S. R. Kim et al., "AMPK activation reduces vascular permeability and airway inflammation by regulating HIF/VEGFA pathway in a murine model of toluene diisocyanate-induced asthma," Inflammation Research, vol. 61, no. 10, pp. 1069-1083, 2012.

[23] X. Zhao, J. W. Zmijewski, E. Lorne et al., "Activation of AMPK attenuates neutrophil proinflammatory activity and decreases the severity of acute lung injury," The American Journal of Physiology: Lung Cellular and Molecular Physiology, vol. 295, no. 3, pp. L497-L504, 2008.

[24] R. Prasad, S. Giri, N. Nath, I. Singh, and A. K. Singh, "5-Aminoimidazole-4-carboxamide-1-beta-4-ribofuranoside attenuates experimental autoimmune encephalomyelitis via modulation of endothelial-monocyte interaction," Journal of Neuroscience Research, vol. 84, no. 3, pp. 614-625, 2006.

[25] S. Giri, N. Nath, B. Smith, B. Viollet, A. K. Singh, and I. Singh, "5-aminoimidazole-4-carboxamide-1- $\beta$-4-ribofuranoside inhibits proinflammatory response in glial cells: a possible role of AMP-activated protein kinase," Journal of Neuroscience, vol. 24, no. 2, pp. 479-487, 2004.

[26] H.-M. Chen, J.-T. Lin, C.-Y. Kuo, and C.-F. Huang, "The effects of novel AMPK activator on human vascular endothelial cells," Journal of Medical and Bioengineering, vol. 3, no. 2, pp. 144-148, 2014.

[27] G. A. Czapski, M. Cakala, M. Chalimoniuk, B. Gajkowska, and J. B. Strosznajder, "Role of nitric oxide in the brain during lipopolysaccharide-evoked systemic inflammation," Journal of Neuroscience Research, vol. 85, no. 8, pp. 1694-1703, 2007.

[28] C. Cantó, Z. Gerhart-Hines, J. N. Feige et al., "AMPK regulates energy expenditure by modulating NAD + metabolism and SIRT1 activity," Nature, vol. 458, no. 7241, pp. 1056-1060, 2009.

[29] X.-D. Yang, E. Tajkhorshid, and L.-F. Chen, "Functional interplay between acetylation and methylation of the RelA subunit of NF- $\kappa$ B," Molecular and Cellular Biology, vol. 30, no. 9, pp. 21702180, 2010.

[30] F. Yeung, J. E. Hoberg, C. S. Ramsey et al., "Modulation of NF- $\kappa$ B-dependent transcription and cell survival by the SIRT1 deacetylase," EMBO Journal, vol. 23, no. 12, pp. 2369-2380, 2004.

[31] Y. Hattori, K. Suzuki, S. Hattori, and K. Kasai, "Metformin inhibits cytokine-induced nuclear factor $\kappa \mathrm{B}$ activation via AMP-activated protein kinase activation in vascular endothelial cells," Hypertension, vol. 47, no. 6, pp. 1183-1188, 2006.

[32] S.-H. Tsai, S.-Y. Lin-Shiau, and J.-K. Lin, "Suppression of nitric oxide synthase and the down-regulation of the activation of $\mathrm{NF} \kappa \mathrm{B}$ in macrophages by resveratrol," British Journal of Pharmacology, vol. 126, no. 3, pp. 673-680, 1999.

[33] I. Sarnico, F. Boroni, M. Benarese et al., "Targeting IKK2 by pharmacological inhibitor AS602868 prevents excitotoxic injury to neurons and oligodendrocytes," Journal of Neural Transmission, vol. 115, no. 5, pp. 693-701, 2008.

[34] M. Pizzi, I. Sarnico, F. Boroni, A. Benetti, M. Benarese, and P. F. Spano, "Inhibition of $\mathrm{I} \kappa \mathrm{B} \alpha$ phosphorylation prevents glutamate-induced NF- $\kappa \mathrm{B}$ activation and neuronal cell death," Acta Neurochirurgica, no. 93, pp. 59-63, 2005.

[35] M. Schwaninger, I. Inta, and O. Herrmann, "NF- $\kappa$ B signalling in cerebral ischaemia," Biochemical Society Transactions, vol. 34, no. 6, pp. 1291-1294, 2006.
[36] G. Zhang, J. Li, S. Purkayastha et al., "Hypothalamic programming of systemic ageing involving IKK- $\beta$, NF- $\kappa$ B and GnRH," Nature, vol. 497, no. 7448, pp. 211-216, 2013. 

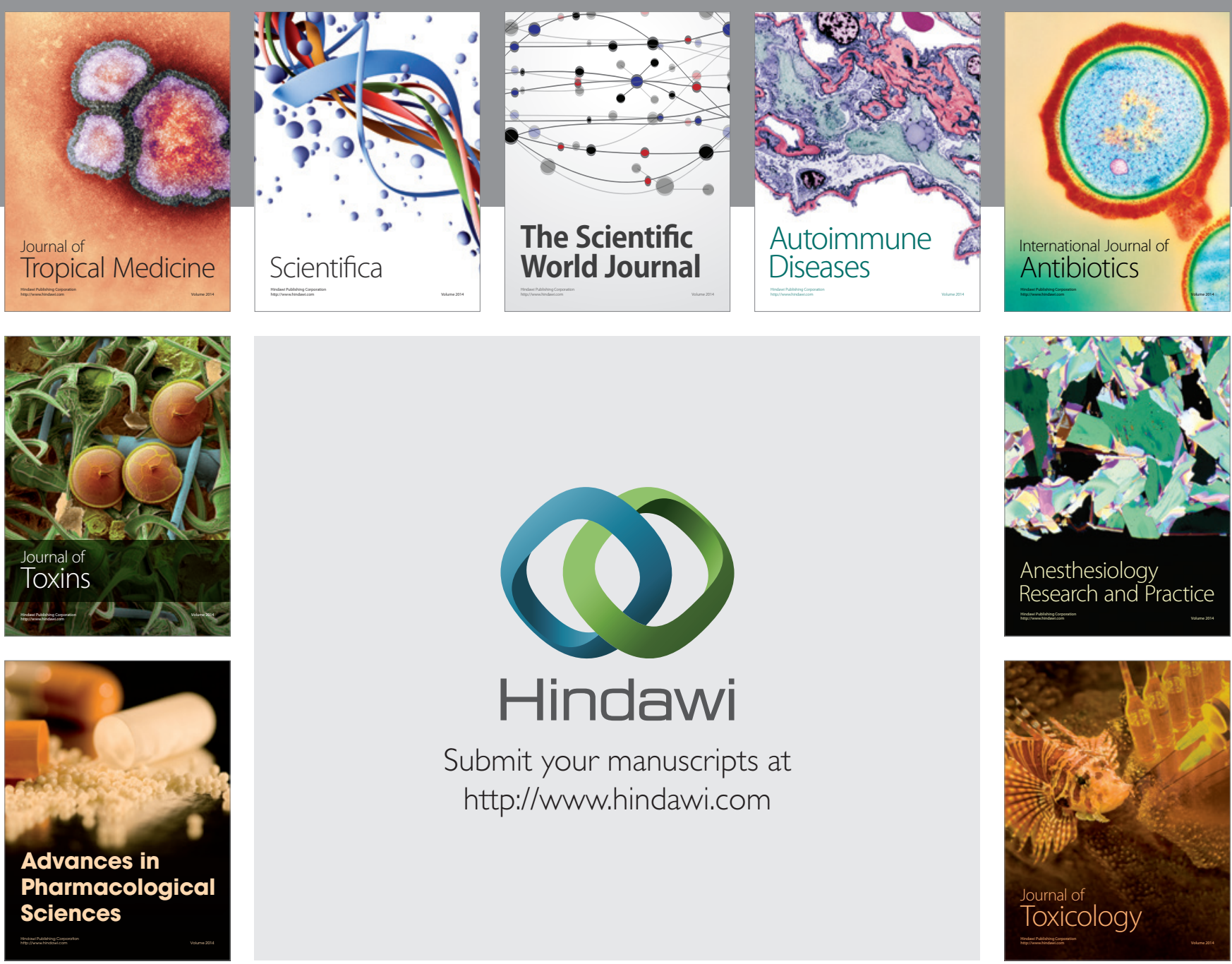

\section{Hindawi}

Submit your manuscripts at

http://www.hindawi.com
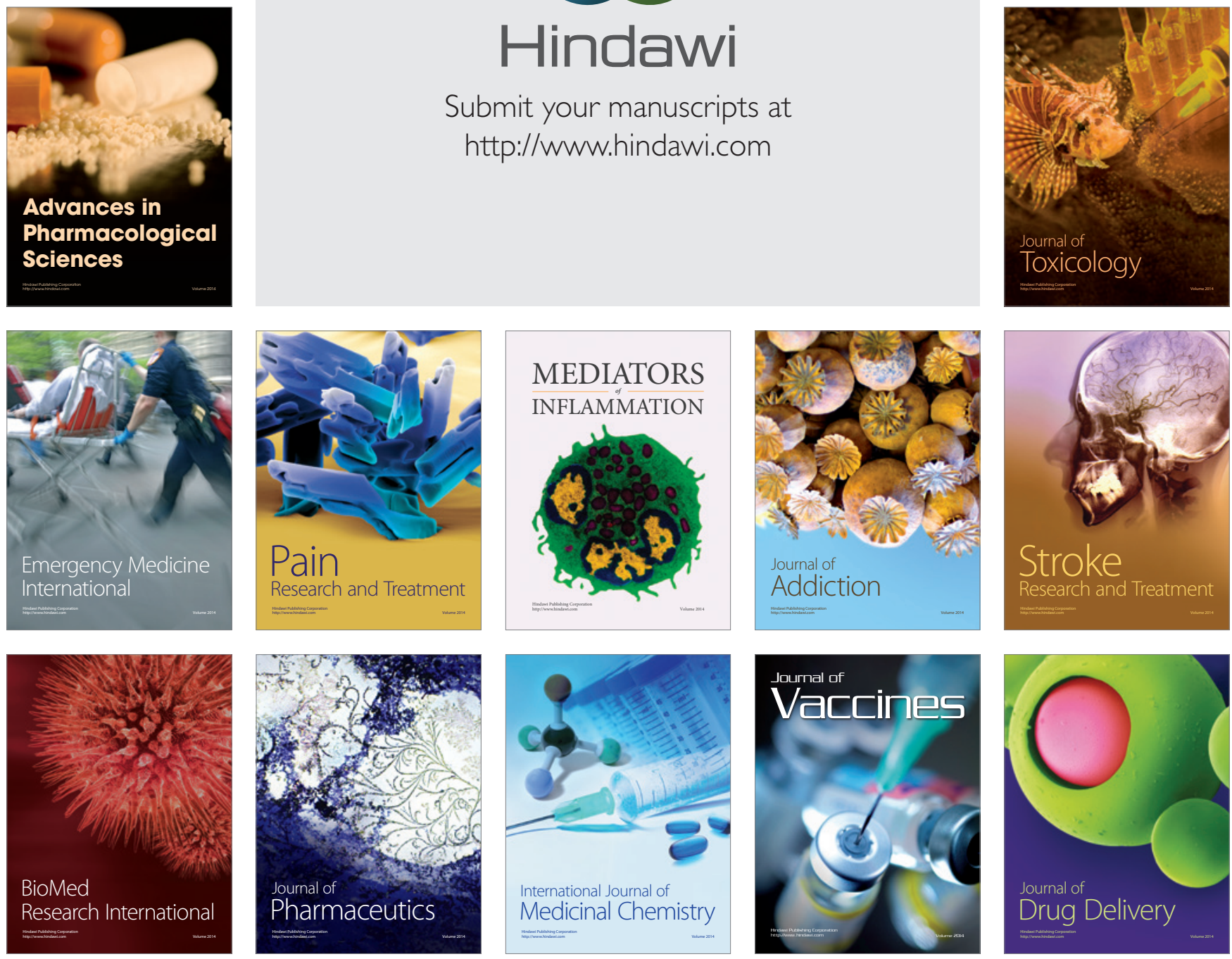